\title{
Serum immunoreactive trypsin in cystic fibrosis
}

\author{
P DANDONA, MARGARET HODSON, J BELL, L RAMDIAL, I BELDON, \\ AND J C BATTEN \\ From the Metabolic Unit and Department of Chemical Pathology, Royal Free Hospital, \\ and the Brompton Hospital, London
}

ABSTRACT Serum immunoreactive trypsin (IRT) concentrations were measured blind in sera from 33 patients with cystic fibrosis and in 32 age-matched controls. Thirty-two patients had abnormal trypsin concentrations. In 30 of these patients the level of IRT was very low whereas in the other two (the youngest of the group) it was extremely high. All 30 patients with low IRT concentrations had clinical or biochemical evidence of malabsorption. Serum IRT concentration may thus be a useful diagnostic test for cystic fibrosis. In view of the recent observation that neonates with cystic fibrosis consistently have raised IRT concentrations, and the fact that the youngest two patients in our series also had markedly increased IRT, it would appear that the initial elevation of IRT reflects early damage to the pancreas with release of enzyme/zymogen; this is thereafter superseded by a progressive destruction of the pancreas resulting in low IRT concentrations in adults with cystic fibrosis.

Cystic fibrosis (CF) is the most common inherited disease in Caucasians but there has hitherto been no adequate established screening test for this condition. Diagnosis depends on the demonstration of a high sweat sodium concentration. The sweat test may be incorrectly performed producing false positive results which lead to wasted time and resources and to invasive investigations on children. ${ }^{1}$ Furthermore, this test cannot be used for neonatal screening.

The emergence of serum immunoreactive trypsin concentration (IRT) as an indicator both of clinically manifest reduction in exocrine pancreatic reserve, as in chronic pancreatitis, ${ }^{2}$ and of subclinical diminution in pancreatic function, as in diabetes mellitus, ${ }^{3}$ provides a new approach to the study of CF. Serum immunoreactive trypsin concentrations in neonates with $\mathrm{CF}$ have recently been shown to be high, ${ }^{4}$ and in this study we tried to evaluate IRT concentration as a diagnostic test for cystic fibrosis.

\section{Methods}

Serum was obtained from 33 patients with known CF (age range: $2 \cdot 5$ to 46 years, with seven patients

Address for reprint requests: Dr P Dandona, Metabolic Unit, Royal Free Hospital, Pond Street, London NW3 2QG. aged less than 12 years) diagnosed on the basis of an abnormal sweat test, and 32 normal, agematched control subjects.

Trypsin in serum was measured by a specific radioimmunoassay (Hoechst) using a double antibody technique. ${ }^{23}$ Trypsin was iodinated with ${ }^{131}$ I using chloramine $\mathrm{T}$. Within-assay variation was $7 \%$ at low concentrations and $2.5 \%$ at high concentrations. Repeat trypsin measurements in the same patients under similar conditions varied less than $20 \%$ at low trypsin concentrations. Serum trypsin concentrations were fairly constant in the normal subject and were not affected by meals or by pancreozymin injection. This assay does not distinguish between trypsin and trypsinogen.

All assays were conducted blind without knowledge of whether the sera belonged to patients or control subjects. Statistical comparisons were made using Student's $t$ test.

\section{Results}

The normal adult range of IRT concentrations as published before is $272 \pm 31 \mu \mathrm{g} / \mathrm{d}$ and that in the

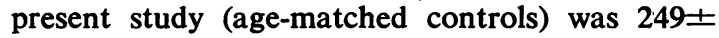
$9 \mu \mathrm{g} / 1$. Thirty out of $33(91 \%)$ sera from patients with CF had low serum IRT concentrations (mean 


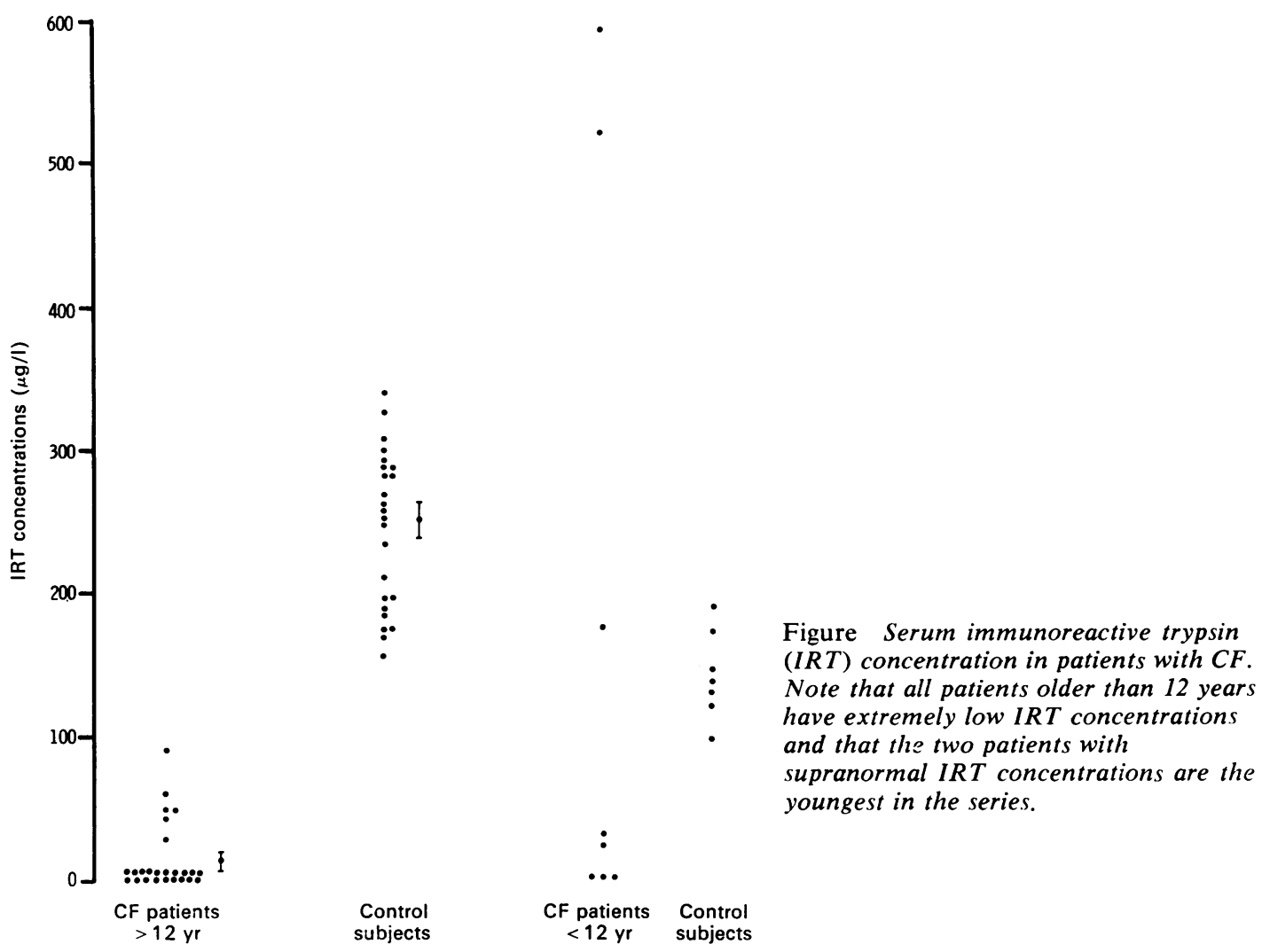

$27 \pm 6 \mu \mathrm{g} / 1)$ of less than $100 \mu \mathrm{g} / \mathrm{l}$, whereas none of the control subjects, except one very young child, had an IRT concentration of less than this value (figure). Two other patients with CF $(6 \%)$ had IRT concentrations higher than any recorded in normal subjects. Only one patient, a child, had IRT concentrations indistinguishable from those in the control subjects. All patients with $\mathrm{CF}$ who had a low or normal IRT concentration had clinical or biochemical evidence of malabsorption or both.

\section{Discussion}

Using IRT concentrations we were able to detect 31 out of 32 patients $(96 \%)$ with CF. Twentynine patients $(91 \%)$ had extremely low IRT levels suggestive of gross pancreatic insufficiency. This is consistent with the known prevalence $(85 \%)$ of pancreatic abnormality in this condition. ${ }^{5}$ All 29 patients with low IRT concentrations had evidence of pancreatic insufficiency and malabsorption, either clinical or biochemical, and were on supplements of oral pancreatic extracts. However the two children with extremely high IRT concentrations also had malabsorption.

Our data thus indicate clearly the usefulness of IRT concentration as a diagnostic test for CF, an extension of its value as a screening test in neonatal infants. Since present developments in the treatment of $\mathrm{CF}$ do not justify an expensive mass screening programme at birth, it is in its role as a diagnostic test that IRT concentration is most likely to be useful.

Low trypsin in the serum would also explain the previous observations that serum protease activity in these patients is low. ${ }^{6^{-8}}$ The pancreas probably contributes significantly to the serum protease activity in normal subjects. Although the role of trypsin in circulation in protein and reptide metabolism is not defined, it is possible that low trypsin activity in the serum could contribute to the accumulation of CF factors in serum, a majority of which are polypeptides. ${ }^{6-9}$

In the present siudy the two youngest patients $(7 \%)$ were shown to have extremely high IRT concentrations. Recent observations on newly born CF homozygotes show that IRT concentra- 
tions are markedly increased. ${ }^{4}$ This implies that a majority of patients with $\mathrm{CF}$ show a progressive fall in IRT concentrations after birth. These observations of supranormal IRT concentrations are consistent with previous suggestions that patients with CF have an uncontrolled and excessive secretion of zymogen granules. ${ }^{10}$ This excess of zymogen probably contributes to an increase in the viscosity of secretions and further inspissation leads to anatomical obstruction and to a chemical, destructive pancreatitis.

In conclusion, our data suggest that IRT concentration is a useful diagnostic test for CF and that a low value of this test might obviate the need for further pancreatic function tests in these patients.

Radioimmunoassay kits for the measurement of trypsin were a gift from Dr RH Roussell of Hoechst, UK. We are grateful to Mrs M Elleman for secretarial assistance. The work was supported by the Cystic Fibrosis Trust.

\section{References}

1 Smalley CA, Addy DP, Anderson CM. Does that child really have cystic fibrosis? Lancet 1978; 2: 415-7.
2 Elias E, Redshaw M, Wood T. Diagnostic importance of changes in circulating concentrations of immunoreactive trypsin. Lancet 1977; 2:66-8.

3 Dandona P, Elias E, Beckett AG. Serum trypsin concentrations in diabetes mellitus. $\mathrm{Br}$ Med $J$ 1978; 2:1125-6.

4 Crossley JR, Elliott RB, Smith PA. Dried blood spot screening for cystic fibrosis in the newborn. Lancet 1979; 1:472-4.

5 di Sant' Agnese PA. Cystic fibrosis. In: Vaughan VC, McKay RJ, Behrman RE, Nelson WE (eds). Textbook of Paediatrics. Eleventh edition. Philadelphia: WB Saunders, 1979:1988.

6 Rao GJS, Nadler HL. Arginine esterase in cystic fibrosis of the pancreas. Paed Res 1974; 8:684-6.

7 Nadler HL. Enzyme studies. In: Mangos JA, Talamo RC (eds). Cystic fibrosis: projections into the future. New York: Grune and Stratton, 1976 285-90.

8 Rao GJS, Posner LA, Nadler HL. Deficiency of kallikrein activity in plasma of patients with cystic fibrosis. Science 1972; 177:610-1.

9 Conover JH, Conod EJ, Hirschhorn K. Studies on ciliary dyskinesis factor in cystic fibrosis. Life Sci 1974; 14:253-66.

10 Blomfield J, Dascalu J, van Lenneo EW, Brown JM. Hypersecretion of zymogen granules in the pathogenesis of cystic fibrosis. Gut 1973; 14:55865. 